\title{
REVIEW JURNAL PENELITIAN
}

KOMODIFIKASI MODEL ENDORSE DALAM INDUSTRI BUDAYA

FASHION DAN KOSMETIKA

(HIPERREALITAS FASHION ENDORSE PADA PRODUK KOSMETIK

DAN BUSANA REMAJA DI MEDIA SOSIAL INSTAGRAM)

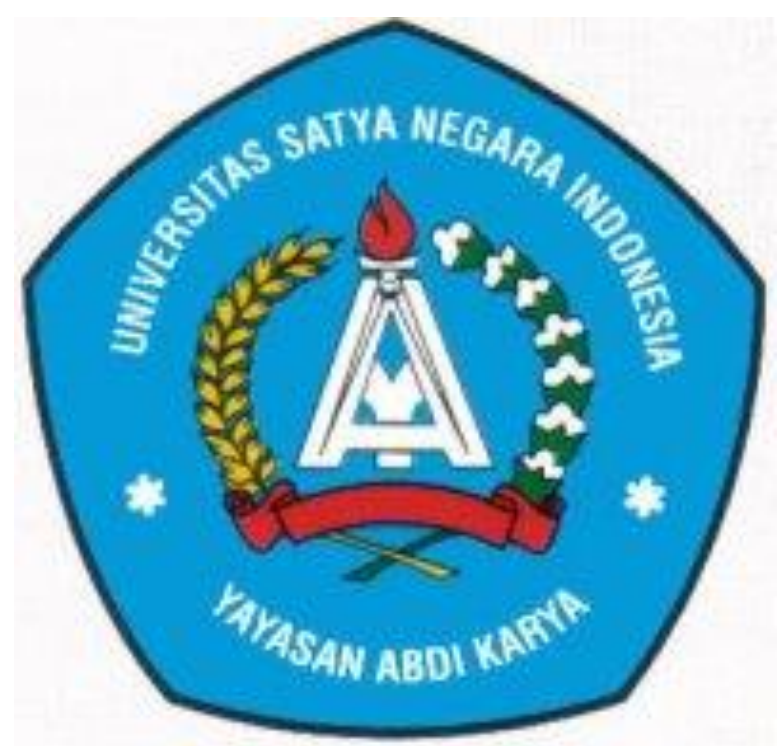

Disusun Oleh:

Lesty Subamin ～(180900017)

Dosen Pembimbing :

Radita Gora Tayibnapis,S.Sos,M.M

\section{UNIVERSITAS SATYA NEGARA INDONESIA}

FAKULTAS ILMU SOSIAL DAN ILMU POLITIK

JL ARTERI PONDOK INDAH NO.11, KEBAYORAN LAMA, RT.4/ RW.2, KOTA JAKARTA SELATAN, DAERAH KHUSUS IBUKOTA JAKARTA, 12240 


\section{KATA PENGANTAR}

Alhamdulillahirabbil 'alamin, rasa syukur kami panjatkan ke hadirat Tuhan yang Maha Kuasa yang telah melimpahkan rahmat-Nya berupa kesehatan, kesempatan serta pengetahuan sehingga makalah Review Jurnal Teori Komunikasi tentang "Komodifikasi Model Endorse Dalam Industri Budaya Fashion Dan Kosmetika (Hiperrealitas Fashion Endorse Pada Produk Kosmetik Dan Busana Remaja Di Media Sosial Instagram)"ini bisa selesai sesuai dengan waktu yang telah ditentukan.

Kami berharap agar makalah ini bisa bermanfaat untuk menambah pengetahuan rekan-rekan mahasiswa pada khususnya dan para pembaca umumnya tentang Komodifikasi Model Endorse Dalam Industri Budaya Fashion Dan Kosmetika (Hiperrealitas Fashion Endorse Pada Produk Kosmetik Dan Busana Remaja Di Media Sosial Instagram) yang merupakan salah satu bagian dari mata kuliah Review Jurnal Teori Komunikasi.

Mudah-mudahan makalah sederhana yang telah kami susun ini bisa dengan mudah dipahami oleh siapapun yang membacanya. Sebelumnya kami meminta maaf bilamana terdapat kesalahan kata atau kalimat yang kurang berkenan. Serta tak lupa kami juga berharap adanya masukan serta kritikan yang membangun dari Anda demi terciptanya makalah yang lebih baik lagi.

Jakarta,06 Oktober 2020 


\section{DAFTAR ISI}

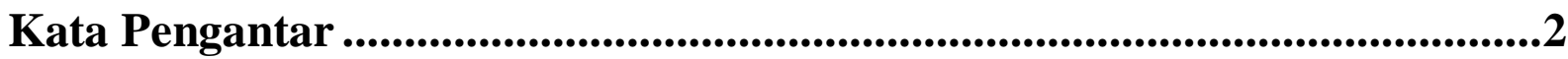

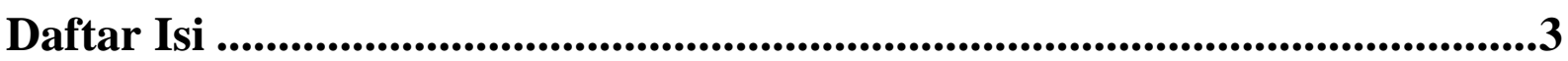

\section{BAB I PENDAHULUAN}

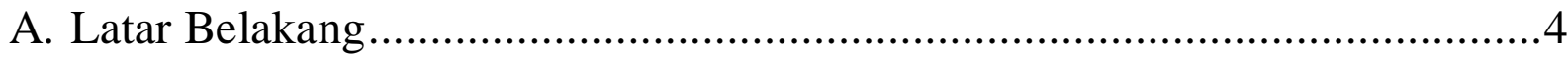

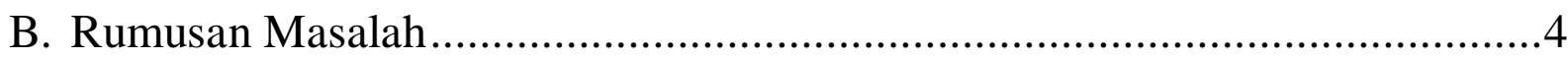

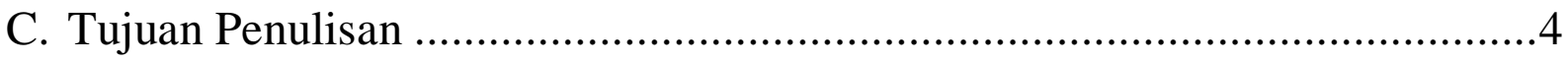

\section{BAB II PEMBAHASAN}

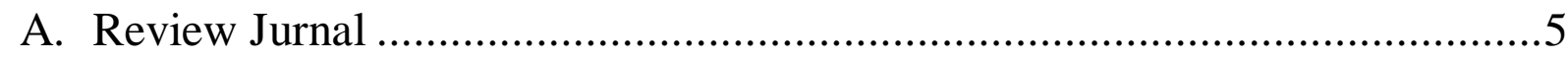

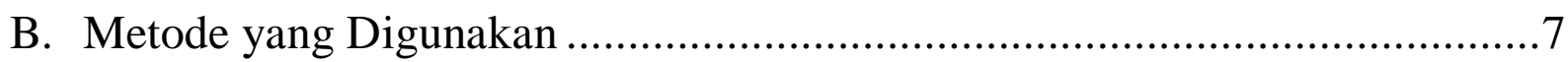

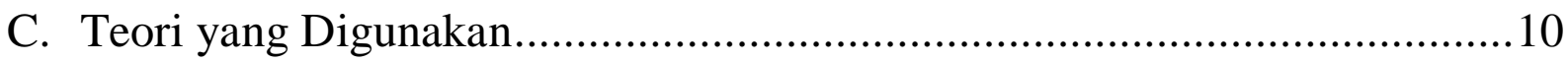

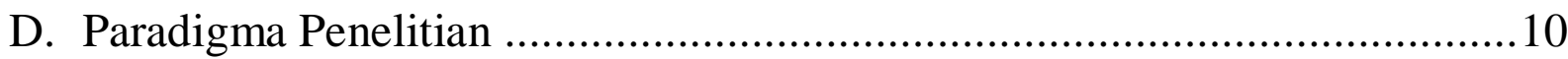

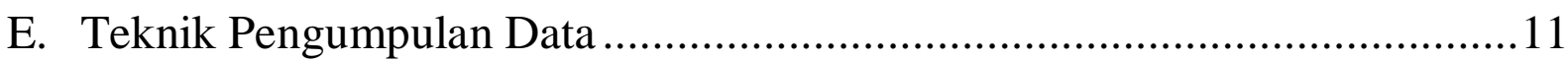

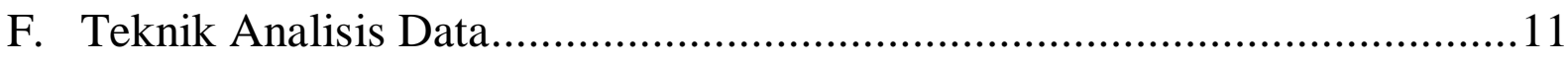

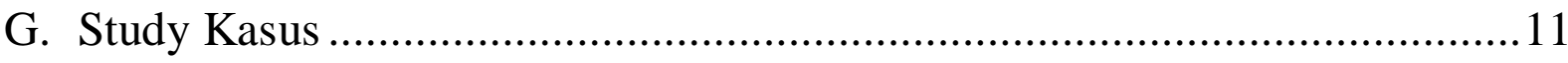

\section{BAB III PENUTUP}

Kesimpulan ..............................................................................................................12

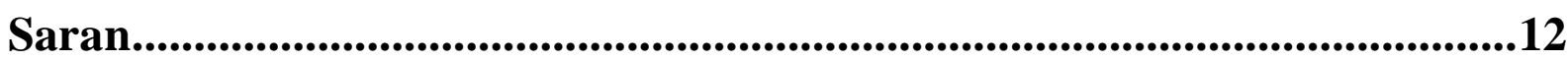

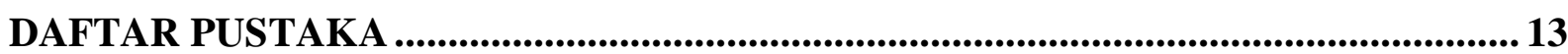




\section{BAB I \\ PENDAHULUAN}

\section{A. Latar Belakang}

Media sosial sebagai bagian dari budaya populer bukan hanya digunakan oleh khalayak luas untuk menampilkan suatu identitas diri melalui perwajahan di internet, melainkan juga dimanfaatkan sebagai sarana berbisnis global. Seperti halnya produk fashion di media instagram sebagai sarana promosinya, termasuk menjadikan publik amatir sebagai model endorse untuk produk fashion dan kosmetika. Namun kegandrungan para remaja menjadi modelini kemudian terlihat sebagai bentuk pemanfaatan tubuh sebagai 'alat jual' untuk mempromosikan produk dan meningkatkan nilai jual produk yang dipromosikan. Sehingga dalam penelitian ini memfokuskan pada persoalan komodifikasi remaja sebagai model endorse di media sosial instragram yang menjadi salah satu media sosial populer di masyarakat.

Saya memilih judul jurnal ini karena isi dari jurnal ini menarik buat saya untuk dibahas. Dan model yang untuk mengendorse cukup menarik untuk dikaji lebih lanjut.

\section{B. Rumusan Masalah}

a) Review lah Jurnal!

b) Metode apa yang digunakan untuk menulis jurnal tersebut?

c) Teori apa yang digunakan untuk menulis jurnal tersebut?

d) Paradigma penelitian apa yang digunakan untuk menulis jurnal tersebut?

e) Bagaimana teknik pengumpulan data jurnal tersebut?

f) Bagaimana teknik analisis data jurnal tersebut?

g) Berikan study kasus yang terkait dengann jurnal tersebut!

\section{Tujuan Penulisan}

a) Untuk mereview jurnal.

b) Untuk mengetahui metode yang digunakan dalam jurnal.

c) Untuk mengetahui teori yang digunakan dalam jurnal.

d) Untuk mengetahui paradigma penelitian yang digunakan dalam jurnal.

e) Untuk mengetahui teknik pengumpulan data yang digunakan dalam jurnal.

f) Untuk mengetahui teknik analisis data yang digunakan dalam jurnal.

g) Dapat memberikan study kasus yang terkait dengan jurnal. 


\section{BAB II \\ PEMBAHASAN}

\section{A. Review Jurnal}

Dalam jurnal tersebut membahas tentang Industri Model Endorse Dalam Industri Budaya Fashion Dan Kosmetika dan juga Busana Remaja Di Media Sosial Instagram. Industri fashion dan kosmetika hingga saat ini masih merajai item-item produk yang ditawarkan di dalam e commerce. Sebagian besar pelaku transaksi e-commerce melalui toko online masih mendominasi transaksi bisnis fashion. Cara berbelanja melalui online juga mengubah kebiasaan masyarakat indonesia dalam berbelanja. Perkembangan internet mengubah cara pandang seseorang dalam membeli barang.

Fashion dan kosmetika, bagi masyarakat modern tidak lagi dianggap sebagai pemenuhan kebutuhan sekunder, namun juga dipandang sebagai kebutuhan primer yang harus terpenuhi. produk kosmetik terus menjadi incaran bagi para khalayak luas terutama yang tersegment pada remaja di tingkat pendidikan Menengah dan pendidikan tinggi.

Produsen baju pun berlomba-lomba untuk membuat media promosi dengan desain iklan yang menarik dimedia digital, eye catching serta menggunakan model-model yang memiliki perawakan dari wajah atau badan yang sesuai dengan penangkapan kamera atau dikenal dengan istilah camera face dan memiliki perawakan yang menjual.

Sehingga dengan begitu dapat mendukung produk agar mudah terjual dengan terus mendengungkan brand (merek) produk di media komunikasi massa digital karena ada ketertarikan konsumen atau calon konsumen terhadap model ataupun produk yang dijual. Keberadaan media digital online bisa dikatakan sebagai perangkat dari media baru yang perlahan mulai mendominasi masyarakat dan juga media lama.

Masyarakat kelas menengah bawah bisa saja membeli baju melalui toko online. Tidak ada strata kelas dalam pembelian barang fashion melalui e-commerce, jadi mereka biasanya sungkan ketika membeli di Mall yang mewah, dan menjadi lebih luwes ketika membeli barang di toko online. Cara berbelanja melalui online juga mengubah kebiasaan masyarakat indonesia dalam berbelanja. Perkembangan internet mengubah cara pandang seseorang dalam membeli barang. 
Alasan orang berbelanja e-commerce, seperti dapat dikirimkan ke rumah dan tidak harus berpergian ke berbagai daerah, ini yang membuat pertumbuhan bagi transaksi online.

Penggunaan model-model endorse pada produk busana, kosmetik dan lain sebagainya kini mulai dipopulerkan kembali sejak adanya kegiatan marketing elektronik dengan menggunakan media online. Yang menjadi model harus memiliki kriteria tertentu dan model tersebut menjadi daya tarik jual beli masyarakat. Sebagian besar pelaku usaha fashion melalui e commerce meyakini bahwa penggunaan endorse mampu mendongkrak penjualan produk busana, di satu sisi para pelaku usaha pun kadang tidak canggung untuk memberikan kompensasi rendah kepada pihak model endorse agar dapat memperoleh keuntungan yang besar dari produk yang dijual.

Produk fashion di media instagram sebagai sarana promosinya, termasuk menjadikan publik amatir sebagai model endorse untuk produk fashion dan kosmetika. Namun kegandrungan para remaja menjadi model ini kemudian terlihat sebagai bentuk pemanfaatan tubuh sebagai 'alat jual' untuk mempromosikan produk dan meningkatkan nilai jual produk yang dipromosikan.

Komodifikasi adalah proses yang erat di kaitkan dengan kapitalisme di mana objek-objek, kualitas-kualitas, dan tanda-tanda diubah menjadi komoditas. Komoditas sendiri dipahami sebagai sebauh barang yang tujuan utama keberadaannya adalah untuk dijual di pasar.

Dalam jurnal tersebut menggunakan produk Nature Republik dengan model wanita hijab dalam pembahasannya.

Produk Nature Republic adalah produk kosmetik sebagai cream pembersih selain mengundang fanatisme pelanggan dalam jumlah besar hingga mengantri dari sisi penjualan termasuk maraknya kasus pemalsuan produk ini sehingga produk ini menjadi incaran distributor dan menggunakan endorse sebagai bagian dari pendukung alat jualnya.

Dengan bahan dasar aloevera, dalam iklan bagus untuk perawatan wajah. Dalam kegunaan lain aloe vera bagus untuk perawatan rambut. Pada tanda ini dimunculkan sebagai upaya untuk mengajak masyarakat atau audiens berpikir tentang kegunaan tanaman lidah buaya. Sehingga upaya mempersuasi khalayak tidak dilakukan secara langsung tentang output hasil dari penggunaan produk kosmetik ini. Namun juga untuk melakukan edukasi terhadap 
masyarakat agar lebih berpikir rasional dalam menggunakan produk kosmetika dan memahami bahan yang digunakan dalam ramuan herbal tersebut.

Dalam mengendorse produk tersebut terlalu mengkaitkan dengan "artis korea". Dalam hal ini, ada unsur 'pemujaan' terhadap sosok artis Korea. Iklan pun menunjukkan adanya peanaman kepada khalayak sebagai tidak mempercayai aktualisasi lokal atau lebih memandang keberadaan figur dari negara lain dibandingkan figur dalam lingkup lokal, sehingga iklan pun terlihat non edukatif dengan mengatasnamakan produk Korea dan membuat khalayak agar memiliki kesadaran palsu tentang perwajahan Korea adalah yang sempurna dan meruntuhkan rasa kepercayaan diri terhadap lingkup lokal.

Figur endorse pun juga tidak relevan dalam menggunakan figur perempuan berhijab dengan busana hitam. Sehingga tidak ada estetika antara penempatan figur dengan warna latar pada visual media promosinya. Begitu pula penempatan endorse pun cenderung dipaksakan dengan tidak memperhatikan estetika penampilan maupun tidak menempatkan perwajahan yang camera face dan tidak menyesuaikan konsepsi perwajahan Korea.

Selain produk Nature Republik, dalam jurnal memberikan study kasus Produk fashion pria Roughneck versi pria remaja dengan konsep street "jalanan" tidak menempatkan posisi Endorse pada komposisi yang estetis, dan tidak memandang sinkronisasi komposisi ojek latar dengan subjek yang difoto. Pada tanda objek yang terlihat pada latar penuh dengan partisi benda-benda sekunder seperti kursi, atau tanaman dan sebuah ruangan sehingga terlihat gaya semi modern antara saat ini dengan jaman dahulu (retro). Adapun penempatan posisi endorse juga tidak menempatkan posisi model secara teratur sehingga estetika model ada kecenderungan tidak bisa menampilkan pasar fashon yang sebagaimana mestinya.

\section{B. METODE YANG DIGUNAKAN}

Dalam penelitian jurnal tersebut menggunakan metode Semiotika. Semiotik atau penyelidikan simbol-simbol membentuk tradisi pemikiran yang penting dalam teori komunikasi. Tradisi semiotik terdiri atas sekumpulan teori tentang bagaimana tanda-tanda merepresentasikan benda,ide,keadaan,situasi,perasaan dan kondisi di luar tanda-tanda itu sendiri. Penyelidikan tanda-tanda tidak hanya memberikan cara untuk melihat komunikasi,melainkan memiliki pengaruh yang kuat pada hampir semua perspektif yang sekarang diterapkan pada teori komunikasi. 
Semiotika menunjukkan bahwa apa yang kita anggap sebagai "alami" atau "jelas" dalam wacana publik perlu dipertimbangkan dalam konteks. Artinya,nilai-nilai kita dan struktur keyakinan yang sering merupakan akibat dari apa yang telah diwariskan dari generasi ke generasi (tradisi). Apa yang di anggap sebagai sesuatu yang "diberikan" tahun lalu hanya mungkin tidak seperti itu hari ini. Semiotika menentang gagasan bahwa kata-kata memiliki makna yang sesuai;memang,kata-kata berubah maknanya seiring dengan orang yang menggunakan kata-kata tersebut juga berubah.

Kebanyakan pemikiran semiotik melibatkan ide dasar triad of meaning yang menegaskan bahwa arti muncul dari hubungan di antara 3 hal yaitu: benda(atau yang dituju), manusi(penafsir), dan tanda.

Contoh simple dari teori ini seperti sebuah cincin di jari manis tangan kiri adalah tanda sudah menikah. Seorang anak kecil menangis dikuburan adalah tanda kesedihan ditinggal seseorang.

Dalam jurnal maka dapat dijelaskan bahwa aspek tanda yang digunakan pada produk iklan kosmetika Nature Republic dilihat dari tiga sisi, yaitu Teks, warna dan figure. Menurut penulis teks pada iklan Nature Republic versi wanita hijab bertuliskan "Pakai Aloevera?" sebagai sebuah teks pertanyaan kata "pakai" yang berarti menggunakan.

Sementara "Aloevera" sebagai sinonim dari tanaman lidah budaya. Dalam aspek Denotasi bahwa tanaman yang digunakan untuk perawatanherbal yang baik untuk kesehatan tubuh dan digunakan untuk perawatan pada kulit wajah dan rambut. Pada tanda ini dimunculkan sebagai upaya untuk mengajak masyarakat atau audiens berpikir tentang kegunaan tanaman lidah buaya.

Pada teks berikutnya adalah "Muka kinclong bak artis Korea?" Pada pertanyaan masingmasing kata pada "Muka" berarti wajah yang dimaknai secara fisik atau "badan" bukan diartikan sebagai diri. Pada bahasa iklan hendaknya menggunakan penggunaan kata-kata baku yang dalam Kamus Besar Bahasa Indonesia (KBBI) penggunaan kata baku merujuk pada "Wajah" sebagai pembentukan pengucapan kata yang sebenarnya dan digunakan pada konten tertentu. Pada iklan ini terdapat kekeliruan penggunaan kata 'muka' yang secara harafiah dimaknai sebagai diri seperti harga diri. Sementara penggunaan kata 'wajah' adalah fisik atau badan manusia. Kemudian pengunaan kata 'kinclong' yang secara sinonim adalah mengkilap. Dengan makna denotasinya dapat diartikan bersih, atau tidak kusam. Hal ini 
juga melanggar dari sisi estetika bahasa dan eika yang tidak termasuk dalam pemenuhan kaidah bahasa yang baku seperti "wajah bersih" atau "wajah terlihat bersih". Sehingga makna dalam iklan pun menjadi jelas dan tidak rancu dengan persoalan estetika bahasa maupun etika penggunaan kata. Subjek teks perlu memandang jarak dengan kahalayak sehingga teks dapat bersifat netral. Jika teks mendekatkan pada segment tertentu, maka ada kecenderungan teks berpihak sehingga nilai kegunaan dari teks menjadi hilang.

Penggunaan kata "kayak artis Korea" kata "kayak" dapat diartikan "seperti" yang juga berlaku interpretasi umum "sama halnya" atau "menyerupai". Kemudian kata "artis" bisa diartikan sebagai pekerja seni. Namun pada kata artis disini bukan dimaknai sebagai pekerja seni secara luas, melainkan memfokuskan pada "artis sebagai selebiritis" atau dalam makna denotasinya adalah orang terkenal atau figur ternama. Hal ini menjadi berhubungan dalam penggunaan kalimat pertanyaan bahwa aspek estetika penggunaan kata, pemilihan kata, serta etika yang digunakan dalam berbicara tidak memperhatikan aspek etika dan estetikanya. Dan terlalu mengkaitkan dengan "artis korea". Dalam hal ini, ada unsur 'pemujaan' terhadap sosok artis Korea.

Pada latar warna secara keseluruhan menggunakan warna latar hijau muda sebagai warna alam dalam pemaknaan denotasi yang identik dengan warna hijau dan juga warna daun. Namun warna hijau juga mengacu pada warna tanaman seperti lidah buaya yang notabene berwarna hijau muda sebagai kualitas tanaman lidah buaya yang baik.

Figur endorse pun juga tidak relevan dalam menggunakan figur perempuan berhijab dengan busana hitam. Sehingga tidak ada estetika antara penempatan figur dengan warna latar pada visual media promosinya. Begitu pula penempatan endorse pun cenderung dipaksakan dengan tidak memperhatikan estetika penampilan maupun tidak menempatkan perwajahan yang camera face dan tidak menyesuaikan konsepsi perwajahan Korea

Selain produk nature republic, peneliti juga membahas Produk fashion pria Roughneck versi pria remaja dengan konsep street "jalanan". Menurut peneliti model Endorse pada komposisi yang estetis, dan tidak memandang sinkronisasi komposisi ojek latar dengan subjek yang difoto. Pada tanda objek yang terlihat pada latar penuh dengan partisi bendabenda sekunder seperti kursi, atau tanaman dan sebuah ruangan sehingga terlihat gaya semi modern antara saat ini dengan jaman dahulu (retro). Adapun penempatan posisi endorse juga tidak menempatkan posisi model secara teratur sehingga estetika model ada kecenderungan tidak bisa menampilkan pasar fashon yang sebagaimana mestinya. 


\section{TEORI YANG DIGUNAKAN}

Teori yang digunakan dalam penelitian ini menggunakan Teori Simulacra menurut perspektif Baudrillad dalam kebudayaan modern. Dalam budaya populer dianggap lebih rendah daripada budaya tinggi Seni dan musik klasik di satu sisi dan budaya rakyat yang otentik di sisi lain. Para pembela distingsi (pembeda) antara budaya tinggi dan budaya populer mendasarkan pada pembeda yang dibuat dan ditunjukkan oleh budaya populer. Budaya populer seringkal dituduh menstandarisasikan dan memerosotkan kualitas seni dan budaya sehingga seni-budaya konformis. Dalam study kasus,kajian simulacra, dapat terlihat bahwa produk fashion maupun kosmetika ini membangun pesan yang bersifat persuasif untuk membentuk suatu simulasi masyarakat yang terlihat seolah tidak membedakan antara realitas fakta maupun diluar realitas. Upaya menanamkan kesadaran kepada konsumen bahwa produk semacam kosmetika nature republic memberikan keyakinan pada masyarakat dengan menggunakan produk tersebut, maka dapat memberikan perwajahan yang bersih seperti halnya figur Korea.

Hal ini pun sesuai dengan perspektif fanatisme masyarakat konsumen terhadap nilai-nilai konsumtif produk dalam memilih produk. Begitu pula dengan produk Roghneck yang memberikan tentang perspektif busana remaja yang bernuansa sederhana dan bisa digunakan dalam segala situasi. Sehingga bagi remaja, untuk gaya berbusana sederhana adalah upaya untuk membangun identitas diri, namun di satu sisi juga mengajak remaja untuk hidup dalam dunai gaya (style) seperti yang digambarkan.

\section{PARADIGMA PENELITIAN}

Metode penelitian yang digunakan dalam jurnal penelitian ini adalah dengan menggunakan penelitian kualitatif melalui analisis teks media iklan promosi di media sosial dengan memaknai tanda dan simbol pada media. Paradigma penelitian yang digunakan dalam penelitian ini menggunakan paradigma kritis. Paradigma ini ingin mengoreksi pandangan konstruktivisme yang kurang sensitive pada proses produksi dan reproduksi makna yang terjadi secara historis maupun institusional. Paradigma kritis, sebagai suatu tradisi intelektual dengan seperangkat keyakinan dalam melihat sebuah fenomena permasalahan secara kritis dengan membedah ideologi, dan sebagai bentuk pencerahan (enlightment) produsen melalui 
teks maupun konteks produk di dalam pemuatannya pada media iklan promosi di media sosial.

Pendekatan Kritis adalah pemahaman pengetahuan yang berhubungan dengan kekuasaan. Para peneliti pendekatan kritis percaya bahwa mereka yang berkuasa membentuk pengetahuan dengan cara mengabdikan status quo. Dengan demikian, orang-orang yang berkuasa berusaha menjaga kekuasaan mereka, sambil membungkam suara-suara minoritas yang mempertanyakan distribusi kekuasaan dan kebenaran versi pemegang kekuasaan.

Pendekatan kritis memiliki tujuan mengubah dunia,yang melibatkan peneliti dengan aplikasi teori untuk menkritisi kasus tertentu.

\section{E. TEKNIK PENGUMPULAN DATA}

Pengumpulan data pada jurnal penelitian ini, peneliti menggunakan korpus materi iklan promosi di media sosial yang termuat di Instagram dengan produsen produk busana (fashion) Roughneck dan produk kosmetika Nature Republic yang masing-masing 1 sampel yang diteliti dengan materi iklan yang telah dipilih oleh peneliti.

\section{F. TEKNIK ANALISIS DATA}

Teknik analisis data yang digunakan pada penelitian ini menggunakan analisis semiotika model Ferdinand De Sassure dan deskripsi penyajian data melalui hasil wawancara dengan Informan yaitu salah satu endorse produk lokal di Indonesia.

\section{G. STUDY KASUS}

Saya mengambil produk kosmetik lipstik Maybelline. Dalam iklan tersebut menggunakan model orang luar negeri. Secara tidak langsung dalam iklan tersebut mengajak kita untuk membeli produk yang ekspetasinya agar terlihat seperti model yang berparas ke baratbaratan. Produk lipstik Maybelline cenderung ke warna yang lebih gelap dan nude. Produk barat berbeda dengan produk Korea. Produk Barat lebih cenderung ke warna gelap sedangkan Korea cenderung warna terang ke peachy. Banyak influencer Indonesia yang mengendorse produk Maybelline ini. Terkadang figur endorse make up nya tidak sesuai dengan produk yang di endorse. Mungkin karena paras yang tidak cocok dengan menggunakan lipstik gelap yang terkesan anatagonis. 


\section{BAB III \\ PENUTUP}

\section{KESIMPULAN}

Dalam jurnal tersebut membahas tentang fashion endorse pada produk kosmetik dan busana pada remaja di media sosial Instagram. Penulis jurnal mengambil contoh kasus pada produk Nature Republik yang menjadi model endorse adalah wanita berhijab. Dan pada produk busana mengambil produk fashion pria Roughneck versi pria remaja dengan konsep street “jalanan”. Penulis jurnal menggunakan teori Simulacra menurut perspektif Baudrillad dalam kebudayaan modern. Dalam penelitian jurnal tersebut menggunakan metode Semiotika. Metode penelitian yang digunakan dalam jurnal penelitian ini adalah dengan menggunakan penelitian kualitatif melalui analisis teks media iklan promosi di media sosial dengan memaknai tanda dan simbol pada media. Paradigma penelitian yang digunakan dalam penelitian ini menggunakan paradigma kritis. Paradigma ini ingin mengoreksi pandangan konstruktivisme yang kurang sensitive pada proses produksi dan reproduksi makna yang terjadi secara historis maupun institusional. Pengumpulan data pada jurnal penelitian ini, peneliti menggunakan korpus materi iklan promosi di media sosial yang termuat di Instagram. Teknik analisis data yang digunakan pada penelitian ini menggunakan analisis semiotika model Ferdinand De Sassure.

\section{SARAN}

Makalah review jurnal ini masih belum sempurna. Adapun saran-saran yang dapat ditujukan kepada diri sendiri,istitusi,peneliti lain,serta pembaca pada umumnya mengenai bagaimana mengantisipasi,menghindarkan atau memperkecil kendala yang dihadapi selama proses pengkajian atau analisis objek kajian. 


\section{DAFTAR PUSTAKA}

(Gora and Olifia)Gora, Radi, and Sandra Olifia. "Komodifikasi Model Endorse Dalam Industri Budaya Fashion Dan Kosmetika.” Ilmu Komunikasi, 2018, p. 14.

Littlejohn, Stephen W., and Karen A. Foss. Teori Komunikasi. Edited by Ria Oktafiani, Salemba Humanika, 2014.

West, Richard, and Lynn H. Tumer. Pengantar Teori Komunikasi Analisis Dan Aplikasi. Edited by Aklia Suslia and Didik Erma Irawan, 5th ed., Salemba Humanika, 2017.

(Littlejohn and Foss)Gora, Radi, and Sandra Olifia. "Komodifikasi Model Endorse Dalam Industri Budaya Fashion Dan Kosmetika.” Ilmu Komunikasi, 2018, p. 14.

Littlejohn, Stephen W., and Karen A. Foss. Teori Komunikasi. Edited by Ria Oktafiani, Salemba Humanika, 2014.

West, Richard, and Lynn H. Tumer. Pengantar Teori Komunikasi Analisis Dan Aplikasi. Edited by Aklia Suslia and Didik Erma Irawan, 5th ed., Salemba Humanika, 2017.

(West and Tumer)Gora, Radi, and Sandra Olifia. "Komodifikasi Model Endorse Dalam Industri Budaya Fashion Dan Kosmetika.” Ilmu Komunikasi, 2018, p. 14.

Littlejohn, Stephen W., and Karen A. Foss. Teori Komunikasi. Edited by Ria Oktafiani, Salemba Humanika, 2014.

West, Richard, and Lynn H. Tumer. Pengantar Teori Komunikasi Analisis Dan Aplikasi. Edited by Aklia Suslia and Didik Erma Irawan, 5th ed., Salemba Humanika, 2017. 